\title{
ANÁLISE DA RELAÇÃO FAMÍLIA/ESCOLA ENTRE \\ DESCENDENTES DE JAPONESES (1950-2000) ${ }^{1}$
}

Hiromi Shibata ${ }^{2}$

Resumo: Com base em estudos sobre capital cultural (BOURDIEU, 1979, 1998, 2007) e relação família e escola (ALMEIDA; NOGUEIRA, 2002; DUBET, 1997; NOGUEIRA; ROMANELLI; ZAGO, 2000; SINGLY, 1997, 2007), este artigo apresenta os resultados da pesquisa realizada entre os anos 2005 e 2008 sobre a natureza do fluxo da demanda de um estabelecimento de ensino privado da capital paulista, por um contingente numérico significativo de descendentes de japoneses, entre os anos 1950 e 1990. Por meio do cruzamento de contextos, buscou-se identificar os critérios que orientaram a escolha da escola, além de situar as famílias pesquisadas no conjunto das mudanças pelas quais passou a sociedade brasileira, no interior da qual a comunidade nikkey foi construindo suas formas de integração e de ascensão social.

Palavras-chave: capital cultural; capital social; escolha da escola; família e escola; estratégias de escolarização de descendentes de japoneses.

Abstract: Based on studies about cultural capital (BOURDIEU, 1979, 1998, 2007) and the relationship between family and school (ALMEIDA; NOGUEIRA, 2002; DUBET, 1997; NOGUEIRA; ROMANELLI; ZAGO, 2000; SINGLY, 1997 and 2007), this article presents the results of the research done between 2005 and 2008 about the nature of the flux of demand in a private institution in the city of São Paulo by a significant number of Japanese descendent between the 50s and 90s. In cross-checking the contexts, the criteria that guided the choice of the school pursued; moreover, this placed the families researched in the set of changes that occurred in the Brazilian society, inside which the nikkey community built their ways of integration and social mobility.

Keywords: cultural capital; social capital; choice of school; family and school; strategies of schooling of the Japanese descendent.

1. Este artigo é uma versão de um dos capítulos da tese de doutorado intitulada Da casa de pau-a-pique aos filhos doutores: trajetórias escolares de gerações de descendentes japoneses (dos anos 1950 aos anos 1990), apresentada pela autora, em 2009, na Faculdade de Educação da Universidade de São Paulo (FE-USP).

2. Docente do Curso de Pedagogia da Universidade Paulista (Unip), São Paulo, Brasil; hiromis@terra. com.br. 


\section{Introdução}

O problema da escolha do "melhor" estabelecimento de ensino para os filhos vem se colocando como um tema de interesse no estudo das relações entre família e escola. Essas relações sempre estiveram presentes nas ações escolares, entretanto, a partir das décadas de 1980 e 1990, em função das novas regras do mercado e, por conseguinte, do sistema escolar, configuraram-se novas formas de interação entre elas. A política educacional, a partir dos anos 1980, ao adotar as forças do mercado como solução para os problemas escolares de custo, de controle e de qualidade, estimulou nas famílias "uma poderosa ideologia do mercado" e uma "cultura da escolha por parte dos pais". Para o sociólogo francês Robert Ballion (1982 apud NOGUEIRA, 1998, p. 54-55), de "usuários cativos", os pais transformaram-se em "consumidores de escola", que buscam o serviço educativo mais adequado a suas demandas, visando a um cálculo custo/benefício e à maximização dos investimentos. Além de "estratégias de consumo", também se entendem as condutas familiares de seleção da escola como "estratégias de classe", indicando que as predisposições para diferenciar as escolas são inconscientes, à semelhança do gosto, e funcionam como uma operação de distinção social.

Conquanto a escolha do estabelecimento se encontre fortemente relacionada com a posição socioeconômica da família, constituindo-se, assim, em um fator de manutenção das desigualdades de oportunidades educacionais, o sistema de valores que interfere na preferência à escola não se reduz à classe social de pertencimento dos pais, mesmo que as possibilidades de escolha e de formulação de estratégias sejam desigualmente acessíveis entre eles, tendo em vista o papel crucial do capital cultural familiar nas condutas de escolha, especialmente quando se trata do capital de informações de que as famílias dispõem sobre o funcionamento do sistema de ensino.

Isso significa poder afirmar que a análise dos critérios de escolha da escola permite avaliar não apenas a posição socioeconômica das famílias, como também encontrar referências para refletir sobre o volume do capital cultural familiar e de sua influência na construção das estratégias educativas para os filhos, voltadas para o sucesso escolar. Nesse quadro, entende-se que, para os pais, o êxito escolar dos filhos passa a depender do veredito escolar ${ }^{3}$.

Entre os objetivos deste artigo, busca-se, por meio do cruzamento de contextos, analisar a natureza do fluxo da demanda de um estabelecimento de ensino privado da capital paulista, por um contingente numérico significativo de descendentes de japoneses, entre os anos 1950 e 1990. Tomou-se como referência um colégio altamente

3. Conforme Beisiegel (1986), os mecanismos criados pelo sistema de ensino não somente permaneceram reproduzindo a desigualdade social como também contribuíram para reforçar o duplo caráter dos vestibulares: ao mesmo tempo em que funcionavam como instrumento importante para regular a relação entre demanda e oferta de vagas no Ensino Superior, os vestibulares serviram também para avaliar a qualidade dos estabelecimentos de Ensino Médio. 
conceituado da cidade de São Paulo, conhecido pelo bom nível de seu ensino e pelo desempenho dos alunos nos exames que envolvem os sistemas de avaliação educacional do país.

Com base em estudos sobre capital cultural (BOURDIEU, 1979, 1998, 2007) e relação família e escola (DUBET, 1997; NOGUEIRA, 2000, 2002; SINGLY, 1997, 2007), busca-se identificar os critérios que orientaram a escolha da escola, além de situar as famílias pesquisadas no conjunto das mudanças pelas quais passou a sociedade brasileira, no interior da qual a comunidade nikkey construiu suas formas de integração e de ascensão social. Pretende-se tanto destacar a condição peculiar dessas famílias de descendentes que optaram pelo investimento no capital escolar como também observar que escolas como esse colégio foram se elitizando ante as exigências do sistema escolar brasileiro ${ }^{4}$.

Este artigo fundamentou-se na pesquisa realizada entre os anos 2005 e 2008 que tomou como referência 20 famílias, sendo 35 entrevistados, entre pais (15) e filhos/ alunos (20), que ingressaram nessa instituição de ensino a partir dos anos 1950. Tomouse como critérios para a constituição da amostra: a época da matrícula no colégio; a quantidade de irmãos ou filhos que foram matriculados na escola; a composição familiar, observando-se o número de integrantes, a presença de avós e a ocorrência de casamento interétnico, além da conclusão do Ensino Médio na instituição. Para procedimentos de análises e de comparações, os pesquisados foram agrupados em: "Geração Colégio 1" compreendendo cinco famílias que matricularam seus filhos entre os anos 1950 e 1970, período que coincidiu com uma fase de desenvolvimento econômico no país, em que as aspirações ascensionais puderam, em grande parte, tornar-se realidade - e "Geração Colégio 2" - compreendendo as 15 famílias que matricularam os filhos entre os anos 1980 e 1990, fase em que as possibilidades de ascensão via escolarização superior tornaram-se mais restritas.

A abrangência histórica e étnica desse colégio constitui um dos motivos de sua escolha. Criado em 1934, o Colégio chama a atenção pela composição étnica de sua população escolar, destacando-se nela os asiáticos e, em especial, os alunos de descendência japonesa. Já no ano seguinte, em 1935, entre 137 alunos matriculados, encontramos um aluno de descendência japonesa. O estabelecimento escolhido constitui referência para estudos que se propõem a abordar a trajetória da educação escolar dos descendentes de japoneses, desde o final da Segunda Guerra Mundial até os dias atuais.

As peculiaridades do grupo de descendentes de japoneses despertam o interesse em investigar os critérios utilizados para a escolha do melhor estabelecimento de ensino. Em um estudo sobre a trajetória escolar de jovens provenientes das camadas médias intelectualizadas, Nogueira, Romanelli e Zago (2000, p. 132) observam que

4. Diante da sofisticação dos exames de acesso às universidades mais prestigiadas, assim como do fato de as famílias da classe média se mobilizarem em torno do sucesso dos filhos, escolhendo as "melhores escolas", estas procuraram se organizar em torno da definição de um estilo de ensino capaz de manter a fidelidade de sua clientela. 
a opção pela "qualidade do ensino" constitui o principal critério de escolha em todos os níveis de escolaridade, embora geralmente associado a outros fatores, como a praticidade (distância da residência, horário e preços), a pedagogia aplicada (inovações pedagógicas e disciplina), tradição familiar (já frequentada pelos pais, avós, irmãos etc.) e mesmo a confessionalidade. Contudo, ressalta que, à medida que se avança na carreira escolar, as razões de ordem prática têm sua importância diminuída no ato da escolha. A preocupação com o vestibular acaba por impor um refinamento no critério da escolha.

Com base nos dados da pesquisa realizada entre os anos 2005 e 2008, é possível afirmar que o crescimento da demanda do Colégio por famílias de descendentes entre os anos 1930 e 1990:

1.tanto se ajustou ao conjunto das transformações ocorridas nos contextos históricos que passaram a impor mudanças no campo educacional;

2. como também respondeu ao aumento do quadro de famílias de descendentes com maiores disponibilidades para altos investimentos escolares.

Fica evidente, portanto, a condição diferenciada dessas famílias que, com provisão de capital socioeconômico e cultural, tiveram condições de escolher o tipo de educação desejado para seus filhos.

\section{A natureza do fluxo da demanda escolar}

\section{Gráfico 1 - Fluxo da demanda - Alunos descendentes de japoneses}

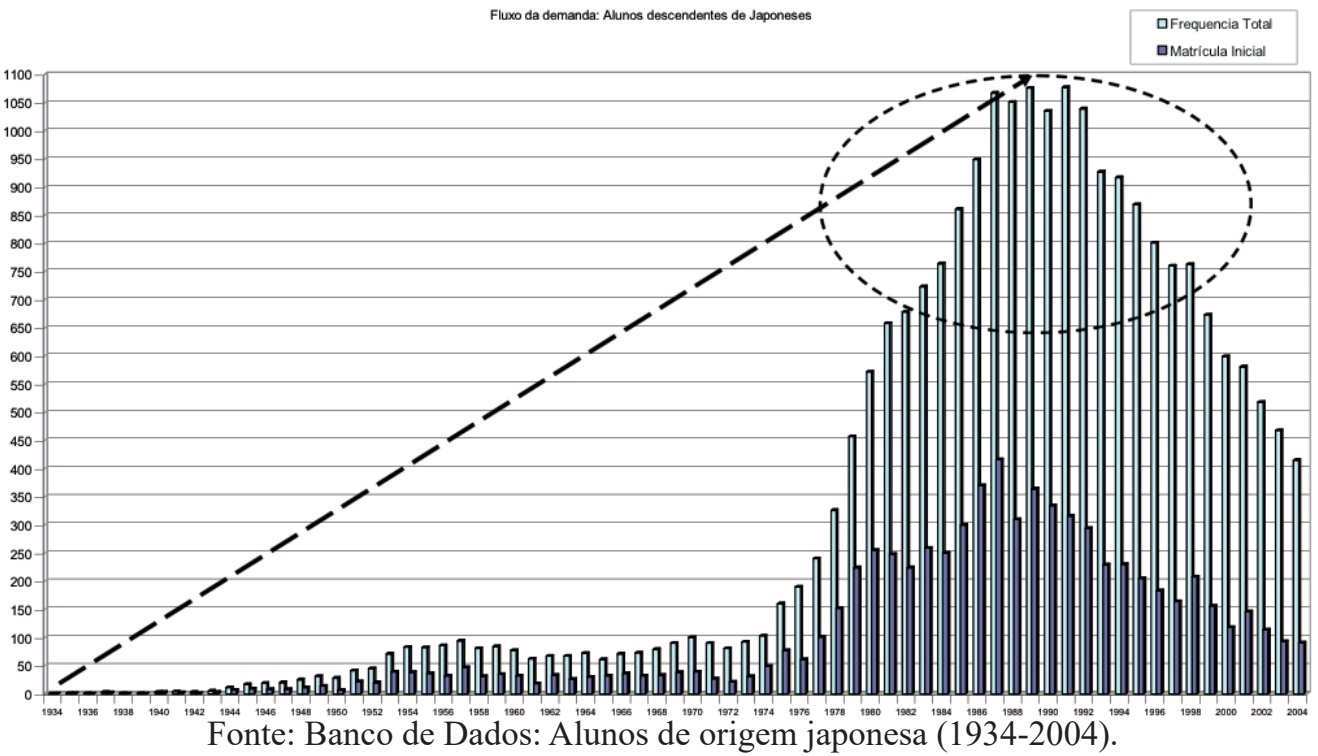


O Gráfico 1 reproduz o movimento geral de entrada dos alunos descendentes de japoneses no colégio enfocado aqui, desde 1935 (entrada do primeiro descendente dessa origem) até 2002, considerando-se a frequência total (alunos descendentes de japoneses que já se encontravam matriculados no colégio) e a matrícula inicial (ingressantes ou alunos novos). A distinção estabelecida entre "frequentes" e "alunos novos" teve a intenção de dar visibilidade ao movimento da demanda, ou seja, de avaliar a redução ou o crescimento das necessidades escolares, para depois qualificar os efeitos do contexto sobre elas.

Com certeza, as diferenças dos fluxos são reflexos das diversas mudanças sofridas pela sociedade a partir dos anos 1930, como consequência do crescimento econômico, das mudanças sociais e políticas, bem como das reformas de ensino no país.

Observa-se o movimento ascendente de 1935 até 1989. Em 1989,31,7\% do total geral era formado por descendentes de japoneses. O ponto alto foi em 1992, quando a população de origem japonesa representou $32,3 \%$ do total do alunado. A partir de 1993, iniciou-se o declínio da demanda, todavia o período que o sucedeu até 2002 permaneceu ainda marcado pela significativa presença de alunos dessa descendência (20\%). O período de 1977 a 2002 compreendeu o "ponto alto da demanda", com a média anual de 237 alunos novos e correspondentes a 23,9\% do total de matriculados no período de 28 anos.

Há três aspectos convergentes que contribuem para explicar esse grande fluxo: 1) a demanda tanto respondeu ao contexto socioeconômico do país no período (euforia econômica decorrente do período do "Milagre" brasileiro - 1969-1973), durante o Regime Militar; 2) quanto à política interna do colégio com a ampliação do espaço físico e a aplicação de mensalidades mais baixas. De 1974 para 1975, a matrícula inicial de descendentes de japoneses cresceu $66,3 \%$ (de 49 para 77 alunos) e a total apresentada na instituição escolar foi correspondente ao aumento de 63,6\% (de 735 alunos para 1.150). E o terceiro aspecto vem do interior do próprio grupo dos japoneses. Conforme vários estudos dos anos 1960 e 1970 já demonstraram (CARDOSO, 1963, 1972; SAITO, 1968; VIEIRA, 1973), um movimento que caracterizou os japoneses e seus descendentes, a partir dos anos 1930, foi sua rápida mobilidade social.

Após a guerra e concomitantemente à migração da área rural para os centros urbanos do interior e da capital, desenvolveu-se uma fase de intensa mobilidade social e ocupacional. Com os sucessos dos empreendimentos agrícolas e mais convictos da necessidade de refazer os planos da imigração, os japoneses buscaram criar as bases de sua fixação no Brasil, investindo em outras atividades fora do setor agrícola, 
especialmente no que se referia às melhores oportunidades educacionais que os centros urbanos ofereciam.

Motivados internamente, grupos de famílias souberam aproveitar as oportunidades de acesso às escolas secundárias e superiores, decorrentes da expansão do sistema educacional a partir dos anos $1930^{5}$, e o sucesso desse empreendimento tanto se expressou no crescimento das matrículas no colégio, a partir dos anos 1950, como também na demanda pelo ensino superior, em São Paulo, na década de 1960, conforme a Tabela 1, a seguir.

\section{Tabela 1 Demanda por Ensino Superior em São Paulo, na década de 1960 (Mackenzie, PUC e USP)}

\section{Origem étnica e posição socioeconômica}

\begin{tabular}{lccccc}
\multicolumn{7}{l}{ (Percentagem de estudantes de cada grupo étnico classificada na posição especificada) } \\
\hline \multicolumn{7}{c}{ Masculinos } \\
Posição socioeconômica & Brasileiros & Latinos & Japoneses & Judeus & Sírio-libaneses \\
\hline \multicolumn{7}{c}{} & 32 & 25 & 12 & 29 & 40 \\
\hline Alta & 49 & 53 & 62 & 71 & 58 \\
Média & 19 & 22 & 26 & - & 2 \\
Baixa & & & & & 40 \\
& 280 & 402 & 128 & 38 & 40 \\
Total 100\% & & &
\end{tabular}

Fonte: GOUVEIA, A. J., 1972, p. 76.

5. Se a tendência demográfica a partir dos anos 1930 foi para o aumento da população em idade escolar (PATARRA, 1986), e se o crescimento econômico favorecido pelo incremento da industrialização impulsionou as escolas secundárias mais que as das outras modalidades de ensino, importa destacar três aspectos que contribuem para analisar a expansão do ensino secundário no país, sob a vigência da Reforma Francisco Campos (1931). O primeiro é que a expansão não se deu somente pelas transformações econômicas geradas pelo início do processo da industrialização, mas que a pressão demográfica decorrente do crescimento vegetativo da população foi uma grande impulsionadora dessa expansão. O segundo aspecto foi o seu caráter excludente que pode ser observado pela pequena parcela da população que efetivamente encontrava-se matriculada nas escolas secundárias do país. E o terceiro está na compreensão de que, ao enfatizar o ensino secundário e o superior, a Reforma Campos (1931) se encontrava, naquele momento, destinada a atender aos interesses das elites e às frações da classe média que estavam preocupadas com a ascensão social. 
Em um contexto marcado pela alta seletividade dos vestibulares ${ }^{6}$ e com base em pesquisas realizadas entre 1967 e 1968, Gouveia (1972) coloca em evidência a presença dos japoneses entre outros grupos étnicos ingressantes nos cursos superiores, nos anos 1960. Para a autora, a presença japonesa em cursos de alta competição, como os da área de Ciência e Tecnologia, indicava a relatividade das condições socioeconômicas como produtoras do sucesso nos vestibulares. Enquanto a posição socioeconômica contribuiu para explicar as altas porcentagens de judeus e sírio-libaneses, o mesmo caso não se aplicou aos japoneses, pois a porcentagem dos que procuraram cursos nessa área, entre os de classe baixa, apareceu maior entre os integrantes da etnia japonesa.

Portanto, descartando a exclusividade do fator socioeconômico para explicar o sucesso escolar dos japoneses e relativizando as hipóteses culturalistas, tais como a importância das disposições psicológicas, a herança cultural japonesa e o grande apreço à educação, a autora destaca a força das circunstâncias históricas em se deu o processo de integração e inserção social dos japoneses na sociedade brasileira, em cujo espaço a educação superior, na área de Ciência e Tecnologia, teria se revelado de utilidade para a ascensão desse grupo minoritário, especialmente.

Não obstante se reconheça o quadro restrito da população que realmente se beneficiou das oportunidades educacionais, é preciso observar que, no quadro subsequente, sob o Regime Militar (1964-1985), em que a posse do diploma de nível superior tornou-se uma necessidade fundamental, a abertura de novos postos de trabalho mais qualificados acabou sendo vantajosa para aqueles que já se encontravam mais preparados pela via da escolarização. Ou seja, naquele contexto, pais portadores de diplomas universitários encontraram espaços para construir suas formas de ascensão social e profissional. A expressão desses benefícios encontra-se traduzida no crescimento das matrículas nesse colégio. Entre 1974 e 1975, no espaço de um ano, a matrícula inicial de descendentes cresceu $66,3 \%$ (de 49 alunos para 77 ).

Se o período do "Milagre brasileiro" (1969-1973), durante o Regime Militar, pode ser tomado como um dos fatores explicativos do crescimento das matrículas e de oportunidades de ascensão social é interessante nos determos no

6. Cf. Gouveia (1972), o descompasso entre a expansão do ensino secundário e a do ensino superior teve como efeito, a partir de 1965, o agravamento do acesso às universidades, com o problema dos excedentes, impulsionando a competição, especialmente em cursos de engenharia e medicina, na área de Ciência e Tecnologia. 
período seguinte, anos 1980, marcado por crises no cenário nacional, quando o crescimento das matrículas revelou um movimento peculiar dos descendentes naquele processo.

Nos inícios dos anos 1980, a combinação entre os efeitos da crise de recessão ${ }^{7}$ e o estreitamento do gargalo de entrada para as carreiras mais seletivas em universidades como a USP, impôs novos desafios às famílias, entre eles, as dificuldades de manter os filhos em escolas particulares, especialmente nas de alto nível, e, ao mesmo tempo, a rigidez dos exames vestibulares, especialmente para as carreiras mais seletivas de universidades como a USP, que passaram a exigir melhor qualificação dos candidatos. $O$ exame vestibular acabou se transformando em um indicador de excelência no momento da escolha das escolas ${ }^{8}$.

Portanto, quando se trata de escolha da escola o fulcro da questão é o acesso à universidades mais prestigiadas, cujos desafios atribuem protagonismo à escola e à família.

A leitura do Gráfico 2 permite observar que existe um comportamento de grupo por parte dos descendentes de japoneses, o qual mostra um fluxo diferente do fluxo geral. Entre os anos 1981 e 1983, encontramos uma tendência decrescente do total geral de matrículas verificadas no período, no entanto, nesse mesmo espaço de tempo, mesmo que se observem leves refluxos, o número de matrículas por parte dos descendentes aumentou.

7. Entre os anos 1981 e 1983, a crise de recessão atingiu, sobretudo, as indústrias de bens de consumo durável e de bens de capital, acompanhada pelas altas das taxas de desemprego e pelo declínio de renda. Apesar de apontar leves declínios, a taxa da inflação continuou alta: $110 \%$ em 1980; 95,2\% em 1981; 99,71\% em 1982. O país viveu, naqueles anos, uma combinação de estagnação econômica e inflação, que se tornou familiar como "estagflação" (FAUSTO, 1995, p. 503).

8. De acordo com a Seade (1989), como reflexo da crise (1981-1983), os governos estaduais tiveram de aumentar as vagas para absorver a demanda que emigrou do ensino privado. Já nos anos 1985-1987, observou-se um ritmo menor de crescimento da rede pública e a retomada da rede privada. Nesse quadro dos anos 1980, não somente os vestibulares se consolidaram como indicadores de excelência na formação escolar dos candidatos, como também as carreiras acadêmicas mais seletivas contribuíram para comprovar a eficácia de determinadas instituições de ensino por meio dos resultados alcançados pelos seus alunos. 


\section{Gráfico 2 - Fluxo das matrículas (1980-1985)}

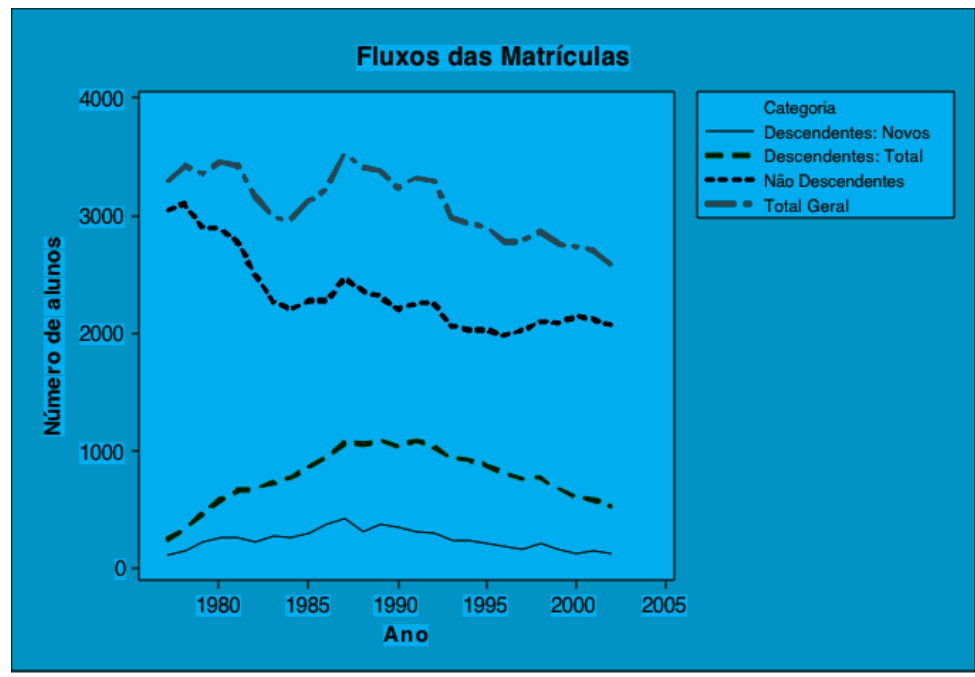

Fonte: SHIBATA, H., 2009, p. 97.

Importa observar os reflexos contrastantes dessas crises no âmbito dos japoneses e de seus descendentes. De um lado, a partir de meados dos anos 1980, como efeito das crises do período, observamos o início do movimento decasségui com brasileiros descendentes de japoneses em busca de trabalho temporário no Japão. De outro lado, enquanto o país conhecia o agravamento dos problemas educacionais e a queda do padrão de escolarização da população, diante da incerteza sobre a qualidade do ensino público, parcelas de famílias de descendentes de japoneses alimentaram as correntes em busca de matrículas em instituições privadas de alto nível de ensino.

Se considerarmos que o crescimento da demanda escolar de descendentes de japoneses atingiu sua fase de grande expansão no período entre 1987 e $1995^{9}$ , coincidentemente marcado pela grande concentração de renda, assim como pelo

9. O exame dos resultados do Saeb (Sistema Nacional de Avaliação da Educação Básica) de 1990, 1993 e 1995, aplicado para alunos do Ensino Fundamental e Médio, da rede pública e privada, mostrou, segundo Vieira (2002, p. 107-111), que tanto quanto aos equipamentos disponíveis na escola como quanto ao desempenho escolar, esses resultados se apresentaram mais favoráveis às instituições privadas, supondo-se, portanto, que as condições de funcionamento das escolas reservadas às camadas economicamente mais favorecidas seriam melhores. Quanto aos indicadores de resultados do ensino superior, estes se apresentavam no sentido inverso. A situação revelou a manutenção de um quadro de desigualdades nas formas de distribuição das diferentes classes sociais no sistema público e privado de ensino. Conforme enfatiza a autora, manteve-se um mecanismo que terminou por preservar às elites econômicas os nichos do privado na educação básica e do público na educação superior, preservando-se, por esse meio, "uma escola para os que podem - a escola de opção - e de outra para os que não podem - a escola dos sem opção" (VIEIRA, 1997, p. 82). 
predomínio do interesse privado sobre o público e pela brutal exclusão escolar, podemos afirmar que a aproximação desse quadro dá visibilidade ao perfil socioeconômico e à posição social da clientela japonesa dessa instituição de ensino. Com pouca margem de erro, podemos afirmar que ela compunha uma parcela seleta da comunidade japonesa paulistana que, tanto pelo poder aquisitivo quanto pelo seu perfil sócio profissional, começava a se diferenciar do restante da população de descendentes de japoneses, percorrendo caminhos ascensionais baseados em projetos de escolarização que se caracterizaram pelo grau maior de sofisticação.

Desse cruzamento de contextos, buscamos extrair não somente informações para fundamentar as razões do grande afluxo de descendentes de japoneses em direção ao referido estabelecimento de ensino, particularmente, a partir dos anos 1980, como, sobretudo, situar as famílias pesquisadas no conjunto das mudanças por que passou a sociedade brasileira, no interior da qual a comunidade nikkei buscou responder aos desafios postos, e, especialmente, às demandas escolares estimuladas pelo mercado de trabalho.

\section{A escolha da escola como forma de adesão ao capital escolar}

Quando analisamos a posição social das famílias, dos anos 1980 e 1990, a partir de suas ocupações, notamos que, ao contrário do período anterior quando na geração dos avós predominaram os agricultores (pequenos proprietários) e os comerciantes, mais orientados para a poupança e menos favorecidos em capital cultural, encontramos $13,4 \%$ dos avós paternos pertencentes aos quadros dos profissionais liberais e empresariais, portanto, situados em ocupações de nível superior. Nas gerações dos pais, aumentaram as frações mais ricas em capital cultural, representadas pelos profissionais empresariais, profissionais liberais, funcionários públicos e professores. Aspecto que nos leva não somente a reconhecer a ampliação do capital escolar, à medida que ocorre o avanço das gerações, como também a colocar em evidência as mudanças sofridas pelas famílias sob o efeito da reprodução escolar.

As famílias dos anos 1980 e 1990 se encontram mais bem equipadas com certo capital cultural e por ocupações de nível superior, em relação às famílias do período anterior. Contudo, um aspecto a ser apontado é o de que se nota, entre as famílias dos dois períodos, o peso maior do capital cultural em relação ao capital econômico, ou seja, na gestão da escolarização dos filhos, o peso dos fatores extraeducacionais (decorrentes da ocupação dos pais) parecem mais frequentes e fortes do que as condições materiais das famílias. Esse aspecto contribui para mostrar que as frações mais bem equipadas de capital cultural puderam responder com maior eficácia às exigências impostas pelo sistema educacional. Decorre disso a especial atenção dada por essas famílias ao ato da escolha da escola, entendendo que a "distribuição do capital cultural se dá na relação entre as estratégias das famílias e a lógica específica da instituição escolar" (BOURDIEU, 1996, p. 35).

Essa ampliação do capital escolar de uma geração à outra é sintomática para 
mostrar que os investimentos escolares realizados pelos avós deram bons resultados, e os pais continuaram a apostar nessa via da escolarização para a inserção social dos seus filhos. A escolha desse colégio dá provas dessa forte adesão das famílias aos valores escolares. Matricular os filhos em uma instituição escolar de forte teor competitivo e de alto grau de investimento passa pela compreensão de que, para essas famílias, somente por meio da frequência a uma escola de bom nível, os filhos poderiam lograr o sucesso nos exames vestibulares mais concorridos, condição fundamental para o ingresso nas carreiras superiores mais prestigiadas.

Segundo os depoimentos dos 35 entrevistados, encontramos uma unanimidade quanto ao principal critério de escolha do colégio como a "melhor escola": a qualidade do ensino associada à pedagogia aplicada, pelo fato de assegurar, em primeiro lugar, uma "boa instrução", e, em segundo, uma "boa profissão". Exigir tarefas e supervisionar os deveres constituíam-se em bens transmitidos aos alunos que, na visão dos pais, orientavam os filhos ao desejo do sucesso e à valorização do trabalho escolar.

A preocupação com o "círculo de amizades" dos filhos também se constitui em elemento norteador da escolha dos pais. A ideia de se criar um "vínculo de pertencimento" a uma instituição escolar tradicional era percebida pelos entrevistados como "símbolo de dignificação" e, portanto, de ascensão social.

As diferenças que encontramos entre as famílias da Geração Colégio 1 e 2 situam-se no grau de refinamento introduzido nos procedimentos de escolha, sob a pressão das mudanças do contexto e do peso relativo do capital cultural familiar de que dispunham. Um sentimento de despreparo cultural levou os pais da Geração 1 a basear suas decisões em opiniões colhidas com pessoas que consideravam mais competentes na matéria. É relevante observar que, se a ascensão dos pais da Geração Colégio 1 prescindiu, em grande parte da escolarização superior, já para os da Geração Colégio 2, esta foi fundamental na reprodução das condições sociais da família, considerandose as mudanças do mercado e as novas exigências postas pelo sistema educacional para o acesso às universidades de maior prestígio. Em sua grande maioria, os pais da Geração 2 são profissionais liberais que alcançaram sucessos profissionais por meio de uma carreira construída com muito esforço e de promoção recente. Na Geração 1, encontramos pais com a escolarização básica, os quais residiam ainda na zona rural, no interior paulista, na época em que o filho estudava no colégio.

Em nossa análise, o comportamento das famílias dos anos 1980 e 1990, constituídas, predominantemente, de pais profissionais liberais, permite aproximá-las do que Ball, Gewirtz e Bowe (1993 apud NOGUEIRA, 1998, p. 44) identificam como os privileged/skilled choosers, ou seja, aquelas que dispõem de "acentuada capacidade de discriminar entre os diferentes tipos de estabelecimentos". São pais vinculados ao campo educacional e com maior capital de relações sociais e, por isso, com o senso prático para responder melhor ao sens $d u$ jeu, mediante um sistema de preferências e de princípios que lhes permitem refinar os critérios de escolha e se beneficiar das oportunidades de uma boa escolarização para os filhos, obtendo "o melhor lucro de 
seu capital cultural" (BOURDIEU, 1996, p. 42). De acordo com Singly (2007, p. 57), poderíamos afirmar que se trata de pais profissionais que se dedicam a um verdadeiro trabalho de conhecimento do meio escolar mais adequado para os filhos.

O depoimento de um dos pais propiciou os fundamentos para essa observação, ao nos revelar o refinamento nos critérios de escolha da escola, com o passar dos anos. Em 1958, quando indicou o colégio para o sobrinho, o critério da escolha denotou uma decisão irrefutável: "Indiquei esse colégio porque era a melhor escola". Vinte anos depois, no momento da escolha da escola para um dos seus filhos, diante da diversidade do mercado de ofertas escolares, suas apreciações tornaram-se mais amplas e a preocupação com a carreira profissional e, por conseguinte, o vestibular impôs um refinamento nos critérios de escolha da escola, de acordo com o avanço dos graus escolares.

A demanda por um colégio cuja reputação é melhor que a da escola em que o filho já se encontra estudando decorre de uma avaliação que leva em conta conhecimentos sobre a estrutura e o funcionamento da instituição escolar. Dispor de informações sobre a estrutura e funcionamento do ensino para formular estratégias de escolha é um tipo de capital cultural que provém não apenas da experiência escolar e profissional vivida pelos pais, mas também de uma rede de informações que envolve amigos e parentes que tenham alguma familiaridade com o sistema escolar. Destaca-se, nesse aspecto, a importância do sistema de relações sociais estabelecido pelos pais, o qual lhes permite obter maiores benefícios com menos recursos. Segundo Singly (2007, p. 57), trata-se de um tipo de demanda que aumenta com a posição social da família e de seu nível cultural, assim como depende da apreciação escolar que os pais têm de seus filhos. A maior atenção quanto ao desempenho do filho e a da escola aparece mais comumente nos relatos das mães que tinham os filhos matriculados nos anos $1980 \mathrm{e}$ 1990.

Quanto à "escolha por área de estudos", importa observar que a preferência das famílias sempre se concentrou em Medicina e Engenharia. Entre os 20 alunos entrevistados, nove se matricularam na Área de Exatas, nove na área de Biológicas e dois em Humanas. Mesmo entre as mulheres, especialmente relativas às alunas da Geração Colégio 1, quando a carreira profissional feminina ainda não fazia parte dos planos de grande parte das famílias da época (anos 1950 e 1960), o tipo da escola escolhida pelos pais já refletia o interesse pelo engajamento feminino em determinadas áreas do mercado de trabalho. A preferência concentrava-se na área de Biológicas, mais conhecida como destinada às carreiras femininas, tais como: Medicina e Odontologia. Dos nove alunos entrevistados, que se matricularam na Área de Biológicas, seis eram do sexo feminino. Duas das entrevistadas escolheram a Área de Humanas.

A formação de uma rede de informações entre as famílias, os amigos e os parentes, contribui para se criar opiniões, entre os pais, sobre as especialidades de alguns estabelecimentos de ensino. Dessa forma, entendemos que a decisão da escolha segundo o critério da "melhor escola", conforme depoimentos dos pais da Geração 1 
e Geração 2, foi também orientada pela "especialidade" da escola em áreas de estudo. Observa-se, quanto aos pais e alunos da Geração 1, uma unanimidade acerca da boa fama do colégio na preparação para os cursos de Engenharia e Medicina.

Além dos depoimentos, uma pesquisa realizada pela Diretoria do Ensino de São Paulo, em 1963, ao mostrar que a maioria dos cursos ginasiais da capital seguia predominantemente um currículo voltado para as Humanidades, acaba se configurando em um forte argumento para justificar a escolha desse colégio pelas famílias interessadas em ver seus filhos seguindo carreiras em Medicina e Engenharia. Denota-se que a escolha do colégio pelas famílias foi orientada pelo fato de essa instituição escolar conservar, durante décadas, sua imagem de uma instituição de ensino "especializada" na preparação para os exames vestibulares nas áreas de Exatas e Biológicas, o que revela, portanto, uma forte identidade entre as preferências das famílias e o tipo de ensino oferecido pela escola.

Assim como encontramos nas entrevistas pouca incidência de critérios de escolha relacionados com a questão das mensalidades, também a distância da residência não parece ter interferido nas decisões das famílias.

Embora não tenha sido enfatizado pelos entrevistados, talvez pela distância do tempo ${ }^{10}$ ou pela pouca idade, na época, o que motivava o desconhecimento exato dos fatos, especialmente quando o depoente era um ex-aluno, o peso das mensalidades transparece em alguns relatos, dando mostras de que a relação custo/benefício com vistas a maximizar os investimentos escolares foi também considerada na formulação das estratégias educativas adotadas, especialmente pelas famílias da Geração Colégio 2, época marcada pelas crises de recessão e de desemprego

Embora a marca japonesa desse colégio não tenha sido nomeada como uma das principais razões da escolha, é preciso observar a existência de uma rede de informações entre os descendentes dessa origem, que atuou para atrair grande parte deles em direção a essa instituição escolar, como, por exemplo o Grupo Caramuru, voltado para o escotismo, em São Paulo.

Matricular os filhos nessa instituição de ensino fez parte do ritual adotado por duas famílias entrevistadas, durante duas gerações. Os primeiros membros das famílias foram matriculados a partir do Ensino Médio (ou Científico, na época), e os mais jovens desde a $5^{\mathrm{a}}$ série. Sem dúvida, a posição social conquistada pelos pais desde a primeira geração dessas famílias permitiu-lhes que, dos anos 1960 aos anos 1990, os filhos e os netos se matriculassem na instituição, seguindo a tradição familiar, como parte de um processo natural na operação da distinção e de reprodução social. Não se trata, pois, de escolha, mas de uma prática que

10. É preciso observar que as respostas dos pais e alunos - por abranger um universo distante, ou seja, o momento da escolha do estabelecimento de ensino ocorrido há mais de 20 anos, para os mais novos, e, aproximadamente, 50 anos, para os mais antigos - podem estar refletindo tanto a motivação real na época como a racionalização posteriormente elaborada. 
se consolida desde a primeira geração entre os membros dessas famílias, predispondo-os a frequentar o colégio como uma marca privilegiada de classe.

A escolha do colégio representou uma etapa decisiva dos projetos construídos por famílias que, não obstante suas peculiaridades, tinham como meta colocar seus filhos em universidades públicas, acreditando assegurar, dessa forma, o acesso a um futuro promissor e às carreiras profissionais de maior prestígio, tanto social quanto econômico. Além de se compreender perfeitamente o lugar da escola, sabia-se também que a instituição assegurava o diploma, bem como a reprodução familiar e, sobretudo, a linhagem de herdeiros. De acordo com Singly (2007, p. 50), "numa sociedade onde o modo de reprodução é baseado na educação escolar", a família perde o poder de designar os herdeiros. Foram esses os motivos que levaram os filhos, os netos e os bisnetos de imigrantes japoneses a se encontrarem no referido colégio, após uma longa trajetória que tem, como marco inicial, a instalação dos avós em zonas rurais e, como limite, a chegada dos pais à capital de São Paulo.

\section{Considerações finais}

O ato da escolha da escola não resultou de uma ação mecânica reduzida meramente à vontade da aspiração social. É certo que o ato de escolher uma escola significou "poder optar" por uma entre outras, mas não se pode perder de vista que toda escolha foi orientada ou condicionada, sobretudo, por um sistema de referências que levou em conta o meio sociocultural ou, conforme Bourdieu (1996, p. 43), a estrutura do capital familiar. Trata-se de sistemas de referências expressas por meio de determinado volume de capitais herdados que priorizam algumas práticas em relação a outras, assim como esquematizam as ações.

Ao depositarmos nosso interesse em investigar alunos egressos desse colégio, delimitamos nosso campo de pesquisa a uma parcela da população de escolarizados que não corresponde ao universo dos japoneses e descendentes que residem neste país. Antes, trata-se de um estudo voltado aos grupos que tiveram a possibilidade de optar, entre os diversos tipos de escola e de ensino, pelo que melhor correspondesse aos seus objetivos.

O tema abordado também contribui para se pensar sobre a questão da desigualdade social, tanto em relação à sociedade como um todo, como entre os japoneses e seus descendentes. Desigualdade que já se apontava no período anterior à guerra, mas que se desponta, de forma nítida, a partir dos anos 1980. A exposição do gráfico das matrículas dessa instituição de ensino é uma demonstração dessa desigualdade, que adquiriu visibilidade a partir dos anos 1980 . E a chave explicativa dessa desigualdade não se encontra necessariamente na posse do capital econômico, mas no capital escolar, ou seja, nas disposições relativas à cultura legitimada pela escola. 


\section{Referências bibliográficas}

BEISIEGEL, C. R. Educação e sociedade no Brasil após 1930. In: FAUSTO, B. (Org.). História geral da civilização brasileira. Tomo III. O Brasil Republicano. v. 4. Economia e Cultura (1930-1964). São Paulo: Difel, 1986. p. 381-416.

BOURDIEU. P. La distintion : Critique sociale du jugement. Paris: Les Éditions de Minuit, 1979.

BOURDIEU, P. O novo capital. In: BOURDIEU, P. Razões práticas: Sobre a teoria da ação. Tradução de Mariza Corrêa. Campinas: Papirus, 1996. p. 7-73.

BOURDIEU, P. Os três estados do capital cultural. In: NOGUEIRA, M. A.; CATANI, A. (Orgs.). Pierre Bourdieu: Escritos de educação. Petrópolis: Vozes, 1998. p. 73-79.

BOURDIEU, P. A economia das trocas simbólicas. São Paulo: Perspectiva, 2007.

CARDOSO, R. C. L. O agricultor e o profissional liberal entre os japoneses no Brasil. In: Revista de Antropologia, São Paulo, v. 11, p. 53-60, 1963.

CARDOSO, R. C. L. Estrutura familiar e mobilidade social: Estudo dos japoneses no Estado de São Paulo. 1972. Tese (Doutorado) - Faculdade de Filosofia, Letras e Ciências Humanas da Universidade de São Paulo, São Paulo, 1972.

DUBET, F. (Dir.) École, familles: le malentendu. Paris: Textuel, 1997. p. 11-41.

FAUSTO, B. História do Brasil. São Paulo: Edusp, 1995.

GOUVEIA, A. J. Origem étnica e situação sócio-econômica dos universitários paulistas. In: Revista de Administração de Empresas, v. 12, n. 1, p. 71-80, jan./mar. 1972.

NOGUEIRA, M. A. A escolha do estabelecimento de ensino pelas famílias. A ação discreta da riqueza cultural. In: Revista Brasileira de Educação, São Paulo, n. 7, p. 42-56, jan./fev./mar./abr. 1998.

NOGUEIRA, M. A.; ROMANELLI, G.; ZAGO, N. Família e escola: Trajetórias de escolarização em camadas médias e populares. 2. ed. Petrópolis: Vozes, 2000.

NOGUEIRA, M. A. Estratégias de escolarização em famílias de empresários. In: ALMEIDA, A. M. F.; NOGUEIRA, M. A. (Orgs.). A escolarização das elites: Um panorama internacional da pesquisa. Petrópolis: Vozes, 2002. p. 49-65.

PATARRA, N. L. Dinâmica populacional e urbanização no Brasil: o período pós-30. In: FAUSTO, B. (Org.). História geral da civilização brasileira: Tomo III. O Brasil Republicano. v. 4. Economia e Cultura (1930-1964). São Paulo: Difel, 1986. p. 246-268.

SAITO, H. O japonês no Estado de São Paulo. In: MARCONDES, J. V. F.; PIMENTEL, 
O. São Paulo: Espírito, povo, instituições. São Paulo: Pioneira, 1968. p. 95-105. SEADE. Educação em São Paulo: uma análise regional. São Paulo: Seade, 1989.

SHIBATA, H. Da casa de pau-a-pique aos filhos doutores: trajetórias escolares de gerações de descendentes japoneses (dos anos 1950 aos anos 1990). 2009. Tese (Doutorado) - Faculdade de Educação, Universidade de São Paulo, São Paulo, 2009.

SINGLY, F. La mobilisation familiale pour le capital scolaire. In: DUBET, F. (Dir.). Ecole, familles : le malentendu. Paris: Textuel, 1997. p. 45-58.

SINGLY, F. Sociologia da família contemporânea. Tradução de Clarice Ehlers Peixoto. Rio de Janeiro: Editora FGV, 2007.

VIEIRA, F. I. S. O japonês na frente de expansão paulista: O processo de absorção do japonês em Marília. São Paulo: Pioneira/Editora da Universidade de São Paulo, 1973.

VIEIRA, S. L. O público e o privado nas tramas da LDB. In: BRZEZINSKI, I. (Org.). Ldb interpretada: diversos olhares se entrecruzam. São Paulo: Cortez, 1997.

VIEIRA, S. L.; ALBUQUERQUE, M. Estrutura e funcionamento da educação básica. Fortaleza: Demócrito Rocha/Uece, 2002. 